Research Article

\title{
Study on Permeability of Steel Slag and Steel Slag Modifying Silt Soil as New Geo-Backfill Materials
}

\author{
Liyan Wang (D), Jiatao Yan, Qi Wang, Binghui Wang $(\mathbb{D}$, and Aimable Ishimwe \\ School of Civil and Architectural Engineering, Jiangsu University of Science and Technology, No. 2 Mengxi Road, \\ Zhenjiang, Jiangsu, China
}

Correspondence should be addressed to Liyan Wang; wly_yzu@163.com

Received 22 December 2018; Revised 26 March 2019; Accepted 17 April 2019; Published 1 July 2019

Academic Editor: Marco Corradi

Copyright (c) 2019 Liyan Wang et al. This is an open access article distributed under the Creative Commons Attribution License, which permits unrestricted use, distribution, and reproduction in any medium, provided the original work is properly cited.

To make steel slag being reasonably used in geotechnical backfilling projects or soft foundation treatment projects, three kinds of steel slag such as fine, coarse, and gravel steel slag were studied through particle analysis tests, relative density tests, and specific gravity tests to obtain basic physical parameters. Considering the influence of relative density, gradation, and other factors, constant head permeability tests of pure steel slag and variable head permeability tests of modified silt soil with different mixing contents of steel slag were carried out to test permeability coefficients under various working conditions. Prediction formulas on the permeability coefficients of the three kinds of pure steel slag and steel slag-treated silt soil were, respectively, deduced. It was concluded that the permeability coefficient of pure steel slag was greatly influenced by particle size and relative density, similar to the case of permeability coefficients of fly ash and fine sand in their dense states, and the larger the relative density was, the smaller the permeability coefficient was. The permeability coefficient of steel slag-treated silt soil increased with increasing of mixing content of steel slag, showing that steel slag can obviously improve the permeability performance of silt soil. Research results provide reference for design and construction on the application of steel slag in roadbed backfill, steel slag modifying silt soil, and other projects.

\section{Introduction}

The permeability coefficient is the penetration velocity, when the hydraulic gradient is equal to 1 , which is an important index of mechanical property that directly measures the permeability of soils. The permeability coefficient of soils is mainly affected by the type of soil, gradation, density, temperature, and other factors, which cannot be calculated and can only be measured directly through tests. The current geological report only provides the value or range value of permeability coefficient, and no corresponding densities of permeability coefficient values are given. It is more scientific to state the corresponding physical state when the given permeability coefficient is given.

There are many studies on the permeability performance of conventional soils so far. A constant head permeameter is used to carry out permeability performance tests on sand with different coarse grain contents, for studying coarse grain effects of sand on the permeability coefficient [1]. It has been found that the more the coarse particles incorporated, the greater the influence on the permeability coefficient.

A higher variability is present in the permeability values of HMA compared to that obtained from cement concrete measurement [2]. Adding a proper amount of recycled glass waste could promote the permeability performance of glasssand soil [3].The lowest permeability is obtained in natural clay, compacted consolidated clay, and compacted clay [4]. Laboratory water retention curve, water permeability, and air permeability tests were carried out to study the effects of compression and biodegradation on intrinsic permeability and the effect of water content on the relative permeability of the borehole specimens.

The dry density has a great influence on the permeability coefficient of compacted and unsaturated loess [5]. It has been found that the permeability coefficient of silty sand decreased with increasing its density, and thus density is an 
important factor affecting the permeability coefficient of soils [6].The permeability characteristics of fly ash added by loess has also been studied, and people proposed that the permeability coefficient of fly ash can be reduced by adding different proportions of loess [7]. Permeability coefficients of red mudstone was also measured under different densities through self-designed "L" model tests [8].The influence of particle size and gradation of soils on permeability coefficients was studied [9]. At present, the generally acknowledged effective particle size $d_{10}$ and porosity ratio $e$ have an impact on the permeability coefficient. However, there was no unified understanding of what forms they, respectively, were in to appear in the theoretical prediction formula of the permeability coefficient.

Disposal of municipal solid waste in the cities has become a complex problem worldwide. Steel slag is a waste generated in iron and steel industry. As the rapid economy development in the world, the waste residue in production process increases year by year with the increase of steel demand. The output of steel slag is more than 100 million tons every year in China, where more than 200 million tons now had been accumulated. It is still increasing by tens of millions of tons annually. Given the large quantities of natural materials used daily in road building, it is necessary to find a way to reduce its adverse environmental impact. Large accumulation of waste steel slag not only occupies a large amount of land but also pollutes the environment and affects the sustainable development of society. The longterm performance of secondary materials is becoming a challenging aspect in road construction since their future behaviour is difficult to be estimated. The use of four kinds of recycled industrial solid waste materials was summed up in asphalt pavements in England, including waste steel slag and waste tires [10]. The sustainability of reusing industrial wastes including waste steel slag and waste tires as energy source was analyzed by Tsai [11] in the industrial sector of Taiwan. Steel slag and crushed stone mixture were used as base materials of flexible pavement to study the influence of steel slag content on the mechanical properties of the mixture [12]. One of the main utilization ways of waste residue is use as a building material, especially the wide application in road engineering and foundation backfill projects, such as foundation, subbase, bearing layer area with noncementitious material being in large demand (antifreeze layer and bearing layer of coarse crushed stones), asphalt mixture base, and even asphalt surface. Thus its application in road and foundation engineering is one of the ways to consume large amount of waste residue easily and economically. However, the road or foundation engineering with higher drainage and antiseismic standards requires the backfill material to have good water permeability.

At present, fly ash produced by using a heat-engine plant is widely used in dam construction and foundation backfill, showing superior engineering performances in many aspects. However, fly ash lacks necessary cohesion, and it reacts sensitively when encountering water, which has a negative impact on safe operation of projects. But studies have shown that steel slag has properties of gelling and cohesion. If the permeability performance of steel slag is good [13], it will be more suitable than fly ash for application in actual engineering of roadbed and foundation. The authors in the paper [14-16] and [17] had studied the related working performances of retaining walls. Seeking a kind of new geomaterial with good permeability to backfill retaining walls is also an important research task to improve the working performance of retaining walls. Therefore, it is necessary to study the permeability performance of steel slag in geotechnical application.

There are many influencing factors on the permeability coefficient of steel slag, and the mechanism is very complicated. No scholars have studied the permeability performance of steel slag so far. In this paper, the permeability performance research of two engineering problems, one is the application of pure steel slag in backfill projects and the other is the steel slag-treated silt soil, is included. First of all, constant head permeability tests of pure steel slag were carried out by considering the relative density, gradation, and other factors, trying to reveal the change law of the permeability coefficient of pure steel slag. Secondly, permeability characteristics of steel slag-treated silt soil were studied by considering different mixing contents of steel slag, trying to reveal the change law of the permeability coefficient of mixtures containing steel slag.

\section{Steel Slag Basic Physical Characteristics Test}

2.1. Particle Analysis Test. The waste steel slag used in the tests was produced by the Yonggang Company in Zhangjiagang City, Jiangsu Province, China. The waste steel slag has been stacked for aging for more than eight months, and it has stable chemical properties; thus it can be directly used in geotechnical engineering. Its natural pile state is shown in Figure 1.

Before the test, the three kinds of steel slag were air-dried in the sunshine and then a small amount of large particles larger than $20 \mathrm{~mm}$ were sieved out.

First of all, the sieve method was adopted to conduct particle analysis tests on steel slag shown in Figure 1, and the results of sieving analysis tests on the three kinds of steel slag are shown in Table 1. In this paper, the three kinds of steel slag were defined for distinguishing them clearly based on the size range. The steel slag whose mass was more than $50 \%$ of the total mass with particle sizes less than $1 \mathrm{~mm}$ was defined as fine steel slag. The steel slag whose mass was more than $50 \%$ of the total mass with particle sizes more than $1 \mathrm{~mm}$ and less than $5 \mathrm{~mm}$ was defined as coarse steel slag. The steel slag whose mass was more than $50 \%$ of the total mass with particle sizes more than $2 \mathrm{~mm}$ was defined as gravel steel slag. And steel slag was distinguished according to the three definitions in the paper.

According to results of particle analysis tests, the grading curves of the three kinds of steel slag were plotted as shown in Figure 2, and their particle size parameters were calculated, as shown in Table 2. Nonuniform coefficients $C_{u}$ of the three kinds of steel slag were all more than 5 , but curvature coefficients $C_{c}$ of fine steel slag and gravel steel slag were 


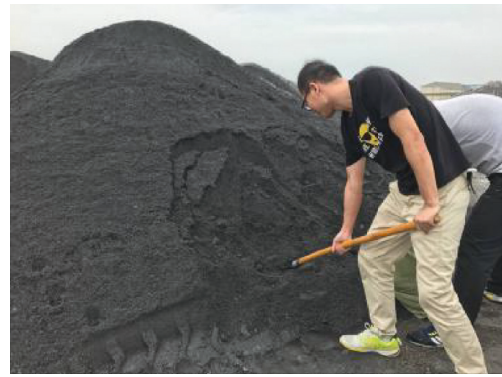

(a)

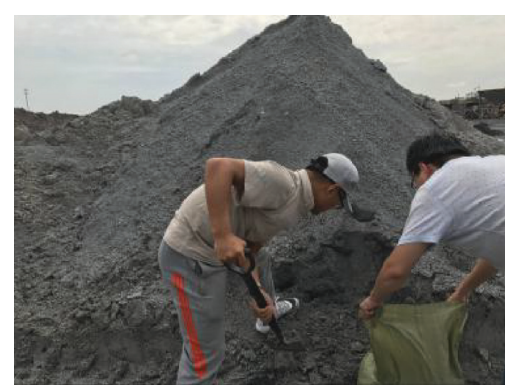

(b)

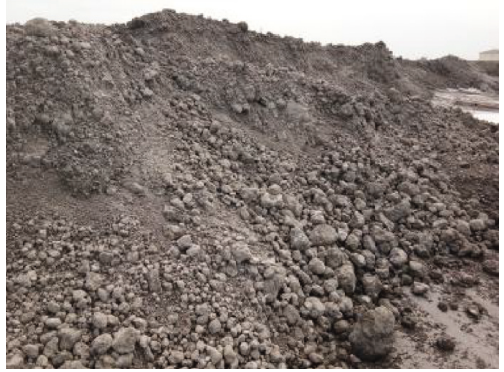

(c)

FIgURE 1: Stacked steel slag.

Table 1: Particle contents in different grain size groups of three kinds of steel slag (\%).

\begin{tabular}{lccccccc}
\hline \multirow{2}{*}{ Materials } & \multicolumn{7}{c}{ Grain size group $(\mathrm{mm})$} \\
& $0 \sim 0.075$ & $0.075 \sim 0.1$ & $0.1 \sim 0.5$ & $0.5 \sim 1$ & $1 \sim 2$ & $2 \sim 5$ & $5 \sim 10$ \\
\hline Fine steel slag & 2.1 & 4.9 & 24.9 & 21.3 & 46.8 & 0 & 0 \\
Coarse steel slag & 0.8 & 7.9 & 14 & 14.1 & 32.2 & 31.0 & 0 \\
Gravel steel slag & 2.1 & 2.2 & 15.7 & 15.4 & 13.6 & 30.2 & 16.6 \\
\hline
\end{tabular}

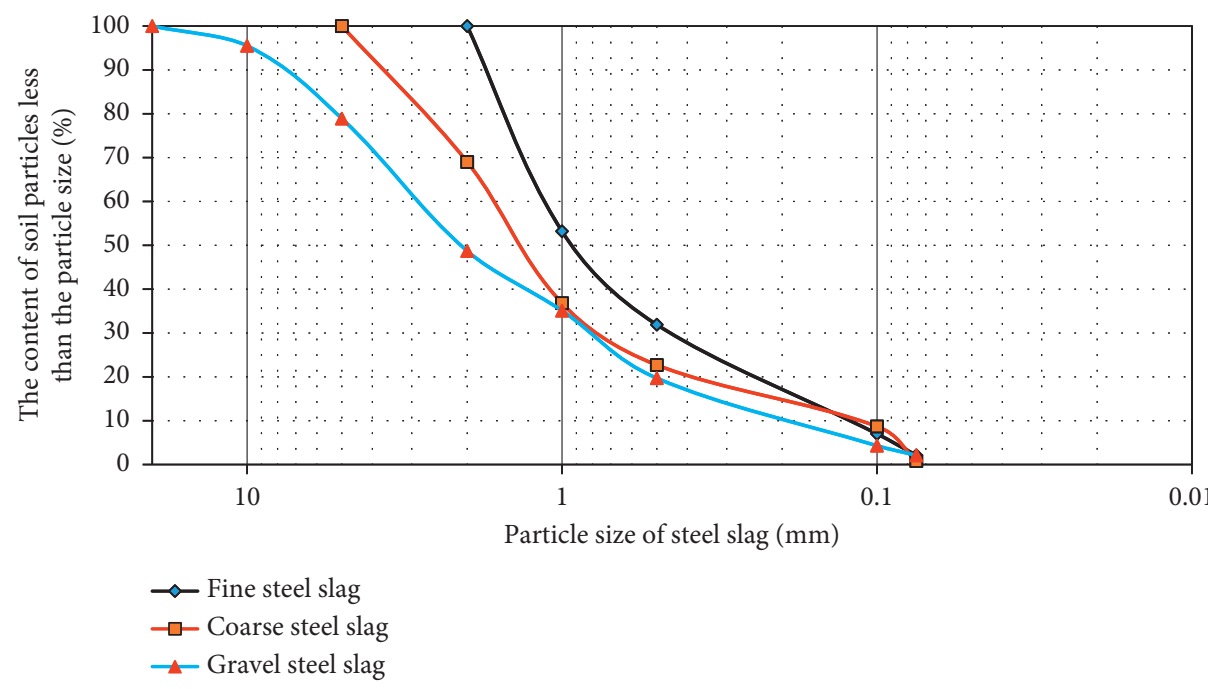

FIGURE 2: Grading curves of three kinds of steel slag.

TABLE 2: Particle size parameters of three kinds of steel slag ( $\mathrm{mm})$.

\begin{tabular}{lcccccc}
\hline \multirow{2}{*}{ Material } & \multicolumn{5}{c}{ Parameter } \\
& $C_{\mathrm{u}}$ & $C_{\mathrm{c}}$ & $d_{10}$ & $d_{30}$ & $d_{60}$ & $d_{50}$ \\
\hline Fine steel slag & 9.38 & 1.3 & 0.13 & 0.45 & 1.22 & 0.91 \\
Coarse steel slag & 13.7 & 3.85 & 0.11 & 0.80 & 1.51 & 1.45 \\
Gravel steel slag & 14.7 & 1.14 & 0.20 & 0.82 & 2.94 & 2.11 \\
\hline
\end{tabular}

both between 1 and 3, and thus they were well graded. And the curvature coefficient $C_{c}$ of coarse steel slag was more than 3 , and thus it was poorly graded.

2.2. Relative Density Test of Steel Slag. One of the controlling factors of constant head permeability tests of pure steel slag was the relative density. Therefore, maximum and minimum dry densities of the three kinds of steel slag need to be measured through tests, and then the relative density could be calculated by using the following formula:

$$
D_{\mathrm{r}}=\frac{\left(\rho_{\mathrm{d}}-\rho_{\mathrm{dmin}}\right) \rho_{\mathrm{dmax}}}{\left(\rho_{\mathrm{dmax}}-\rho_{\mathrm{d} \min }\right) \rho_{\mathrm{d}}},
$$

where $\rho_{\mathrm{d}}$ is the dry density of steel slag, $\rho_{\mathrm{dmin}}$ is the minimum dry density, and $\rho_{\mathrm{dmax}}$ is the maximum dry density.

The minimum dry density was measured by adopting the funnel method, and the maximum dry density was measured with the hammering method. Test materials are shown in Figure 3. Two parallel experiments were conducted, and their average value was taken when their difference was less than $0.03 \mathrm{~g} / \mathrm{cm}^{3}$.

The maximum and minimum dry densities of the three types of steel slag obtained by tests are shown in Table 3. $\rho$ is 


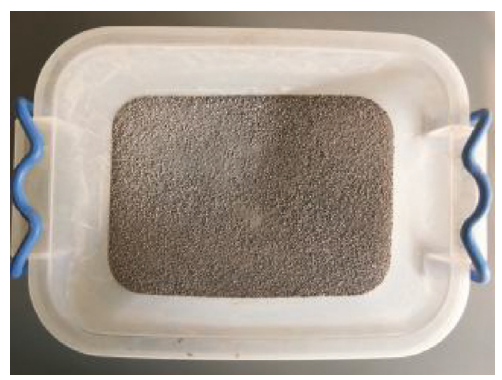

(a)

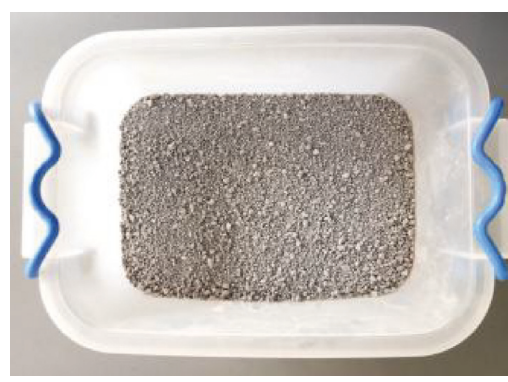

(b)

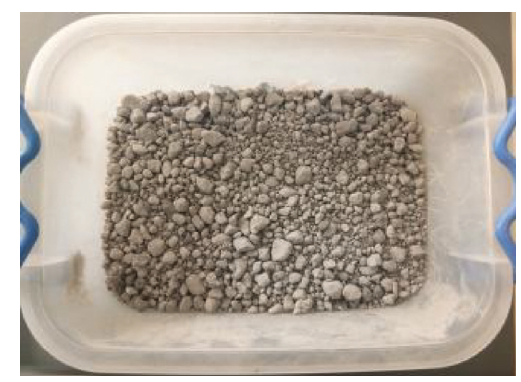

(c)

Figure 3: Test materials. (a) Fine steel slag. (b) Coarse steel slag. (c) Gravel steel slag.

TABle 3: Maximum and minimum dry densities of three kinds of steel slag $\left(\mathrm{g} / \mathrm{cm}^{3}\right)$.

\begin{tabular}{lccc}
\hline Material & & \multicolumn{2}{c}{ Density } \\
& Maximum dry density $\rho_{\text {dmax }}$ & Minimum dry density $\rho_{\text {dmin }}$ & Natural density $\rho$ \\
\hline Fine steel slag & 2.58 & 1.96 & 2.17 \\
Coarse steel slag & 2.53 & 1.95 & 2.10 \\
Gravel steel slag & 2.40 & 1.57 & 1.77 \\
\hline
\end{tabular}

the sample density and represents the density of the steel slag in the natural state called natural density.

2.3. Specific Gravity Test of Steel Slag. The specific gravity of steel slag is the actually measured index, whose accuracy directly affects the accuracy of other indicators. The pyknometer method was adopted for tests because particle sizes of coarse and fine steel slag were all within $5 \mathrm{~mm}$, and a suspending weigh method was adopted for tests because particle sizes of gravel steel slag were more than $5 \mathrm{~mm}$ accounted for nearly $20 \%$.

The measured specific gravity values are shown in Table 4 and compared with conventional soils. It was concluded that the specific gravity of the three kinds of steel slag were all larger than that of conventional soils, and the specific gravity of fine steel slag and coarse steel slag was similar. The specific gravity of gravel steel slag was smaller than that of coarse and fine steel slag, but it was greater than that of conventional soil such as sand.

\section{Permeability Characteristics Test of Pure Steel Slag}

3.1. Test Scheme. The permeability coefficient of soils is affected by many factors, including the gradation of soil particles, relative density, shape of soil particles, and temperature. In this paper, two factors of relative density and particle gradation were mainly considered, and a total of 18 groups of tests under conditions of three gradations were carried out. The relative density was controlled with the wooden hammer compaction method. Each group of three parallel experiments was conducted at room temperature. In order to eliminate the influence of temperature, water temperature was tested during tests. Final test results were finally revised to permeability coefficients at $20^{\circ} \mathrm{C}$. The setting level on relative densities of the three kinds of steel slag in permeability tests is shown in Table 5.

3.2. Test Equipment and Test Methods. The test equipment is a TST-70-type permeameter, as shown in Figure 4. The height of the cylinder is $40 \mathrm{~cm}$, the inner diameter is $10 \mathrm{~cm}$, the bottom surface area is $A$, and the spacing of the two piezometer tubes is $L$. The constant head method was adopted for tests. Water for tests was degassed by the boiling method, and the water temperature during tests was higher than the indoor temperature 3 to $4^{\circ} \mathrm{C}[20]$.

Dry steel slag of $6 \mathrm{~kg}$ was taken in the test, and steel slag was placed into the cylinder in 12 layers. In order to keep same relative density of each layer, same quality of steel slag was placed in each layer and then the wooden hammer was used to gently compact every layer to a uniform thickness of $2.5 \mathrm{~cm}$. The stopping water clip was opened slowly after each layer was placed, water slowly infiltrated from the bottom of bucket until the sample was saturated. Water flow for saturating the sample should not be too fast to prevent the sample from getting break. The stopping water clip was closed when water just reached the top of each layer, and then steel slag was placed in the next layer. The sample was loaded in layers and saturated, which was stopped until the top of the sample was $5 \mathrm{~cm}$ below the top of the cylinder to ensure that the sample height was $30 \mathrm{~cm}$. Then, the quality of the residual steel slag was weighed, and the total mass of the sample was calculated. The steel net gasket was placed above the sample as a buffer layer and water was released, and then the stopping water clip was closed when water surface was about $2 \mathrm{~cm}$ above the gasket.

The water supply pipe was separated from the water transfer pipe, and the water supply pipe was placed in the cylinder, and then the stopping water clip was open to make water injected to the cylinder until water surface reached the height of the overflow hole. After standing for 2 minutes, the 
TABLE 4: Comparison of specific gravity between three kinds of steel slag and conventional soils.

\begin{tabular}{lcccccc}
\hline Soil type & Fine steel slag & Coarse steel slag & Gravel steel slag & Sand [18] & Clay [18] & Fly ash [19] \\
\hline Specific gravity & 3.57 & 3.63 & 3.10 & 2.65 & 2.75 & 2.35 \\
\hline
\end{tabular}

TABLE 5: Setting levels of relative density considered in permeability tests.

\begin{tabular}{llllll}
\hline Consideration factor & \multicolumn{5}{c}{ Relative density (\%) } \\
\hline Fine steel slag & 10 & 20 & 40 & 50 & 60 \\
Coarse steel slag & 10 & 20 & 40 & 50 & 70 \\
Gravel steel slag & 10 & 20 & 40 & 50 & 60 \\
\hline
\end{tabular}

The value is the design value of the relative density, and the analysis of results was based on the measured values.

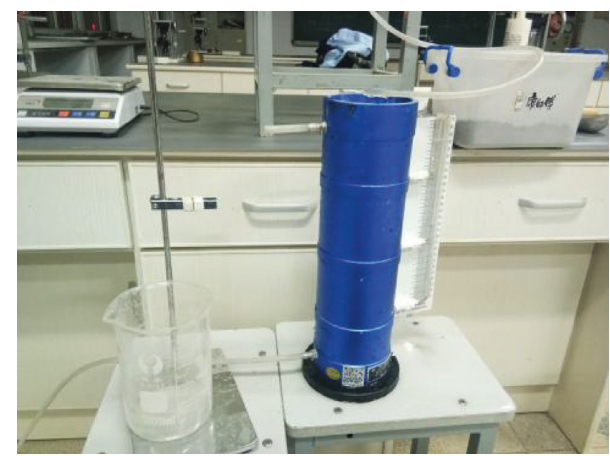

FIGURE 4: TST-70-type permeameter.

nozzle position of the adjustment pipe was reduced until water levels of every piezometer tube and the overflow hole were at the same height. After water permeating through the sample and then outflowing from the adjustment pipe, the stopping water clip was adjusted for keeping water continuously drip off the overflow hole so that maintanance of water level in the barrel unchanged all the time. After the water level of the piezometer tube becoming stable, the water level value on the piezometer tube was read and the water level difference was calculated. The stopwatch was started for recording the infiltration time $t$, a certain amount of water $Q$ was collected in the cylinder at the same time, and water temperatures at the inlet and outlet of the cylinder were recorded, taking their average value $T$.

The nozzle of the adjustment pipe was reduced to the position of the middle and $1 / 3$ of the sample, changing the hydraulic gradient $H / L$. Above operating steps were repeated to continue the measurement.

\subsection{Test Results and Analysis}

3.3.1. Calculation Method. The permeability coefficient of steel slag was calculated according to the following formula. Results of parallel experiments of the three kinds of steel slag under different relative densities are shown in Table 6:

$$
k_{\mathrm{T}}=\frac{Q L}{A H t},
$$

where $H$ is the average water level difference $(\mathrm{cm}), L$ is the distance between the center of the two piezometer tubes, and $Q$ is the seepage quantity within time $t$.
It was found that results of parallel experiments in each group decreased in turn during tests. The reason may be that steel slag exhibited slight expansibility when encountering water. At the start of the infiltration, the seepage speed was fast because there were many pores in the steel slag due to the fact that they were not completely dense. As the permeation time becoming longer, steel slag expanded slightly and the volume of pores decreased, resulting in the hindrance of permeation, thus decreasing the infiltration capacity. During test process, the situation that piezometer tube readings often appeared unstable or even no readings occurred, which was due to the uneven compaction in the process of making the sample in layers, resulting in different permeability performances of different parts of the sample, and thus the water pressure inside the sample was abnormal. Therefore, rigorous sample preparation process was the basis for success of this experiment.

The permeability coefficient of steel slag at the standard temperature was calculated according to the following formula, and the obtained results are shown in Table 7:

$$
k_{20}=k_{\mathrm{T}} \frac{\eta_{\mathrm{t}}}{\eta_{20}}
$$

where $k_{\mathrm{T}}$ is the permeability coefficient at water temperature of $T^{\circ} \mathrm{C}, k_{20}$ is the permeability coefficient at standard water temperature of $20^{\circ} \mathrm{C}(\mathrm{cm} / \mathrm{s})$, and $\eta_{\mathrm{t}} / \eta_{20}$ is the viscosity coefficient ratio obtained from the standard for the soil test method.

\subsubsection{Relationship between Permeability Coefficient and} Relative Density. Relationship curves $k-D_{r}$ between the permeability coefficient and the relative density were drawn in the coordinate system, as shown in Figure 5. It can be seen that permeability curves of different steel slag have the same characteristics. (1) The larger the relative density of steel slag, the smaller the permeability coefficient, which is due to the larger the relative density, the greater the compactness of steel slag and the smaller the internal pores, and the gap between large particles was filled with small particles and air in pores was compressed, thus increasing the resistance of free water flow. (2) Permeability coefficients of fine steel slag and coarse steel slag decreased slowly when the density was lower and less than $30 \%$. The inflection point appeared in permeability curves with the relative density between $40 \%$ and $60 \%$, and the permeability coefficient decreased sharply. 
TAвLE 6: Permeability coefficients of parallel experiments under different relative densities.

\begin{tabular}{|c|c|c|c|c|c|c|c|c|}
\hline Material & $D_{\mathrm{r}}(\%)$ & $k_{\mathrm{T}}\left(10^{-3} \mathrm{~cm} / \mathrm{s}\right)$ & Material & $D_{\mathrm{r}}(\%)$ & $k_{\mathrm{T}}\left(10^{-2} \mathrm{~cm} / \mathrm{s}\right)$ & Material & $D_{\mathrm{r}}(\%)$ & $k_{\mathrm{T}}\left(10^{-3} \mathrm{~cm} / \mathrm{s}\right)$ \\
\hline \multirow{18}{*}{ Fine steel slag } & \multirow{6}{*}{30.68} & 6.96 & \multirow{18}{*}{ Coarse steel slag } & \multirow{3}{*}{8.93} & 7.91 & \multirow{18}{*}{ Gravel steel slag } & \multirow{3}{*}{38.32} & 9.23 \\
\hline & & 6.44 & & & 7.51 & & & 7.52 \\
\hline & & 6.19 & & & 7.73 & & & 6.37 \\
\hline & & 6.48 & & & 7.49 & & \multirow{3}{*}{49.65} & 28.3 \\
\hline & & 6.39 & & 33.21 & 7.50 & & & 26.1 \\
\hline & & 6.31 & & & 7.21 & & & 17.1 \\
\hline & \multirow{4}{*}{44.72} & 5.58 & & & 7.07 & & \multirow{4}{*}{66.07} & 9.24 \\
\hline & & 5.13 & & 47.07 & 7.41 & & & 9.09 \\
\hline & & 4.54 & & & 6.74 & & & 8.91 \\
\hline & & 4.14 & & & 0.71 & & & 6.92 \\
\hline & \multirow[t]{3}{*}{46.40} & 4.01 & & 53.44 & 0.64 & & \multirow[t]{3}{*}{68.02} & 6.43 \\
\hline & & 3.88 & & & 0.53 & & & 6.01 \\
\hline & & 3.42 & & & 4.11 & & & 1.13 \\
\hline & \multirow[t]{3}{*}{65.63} & 3.34 & & 59.67 & 3.28 & & \multirow[t]{3}{*}{71.73} & 0.95 \\
\hline & & 3.33 & & & 2.91 & & & 0.81 \\
\hline & & 3.12 & & & 3.22 & & & 1.17 \\
\hline & \multirow[t]{2}{*}{74.80} & 3.14 & & 69.21 & 3.17 & & \multirow[t]{2}{*}{78.22} & 0.68 \\
\hline & & 2.98 & & & 2.46 & & & 0.49 \\
\hline
\end{tabular}

TABle 7: Permeability coefficients of three kinds of steel slag at standard temperature.

\begin{tabular}{|c|c|c|c|c|c|c|c|}
\hline Material & Number & $D_{\mathrm{r}}(\%)$ & $e$ & $k_{\mathrm{T}}(\mathrm{cm} / \mathrm{s})$ & $T\left({ }^{\circ} \mathrm{C}\right)$ & $\eta_{\mathrm{t}} / \eta_{20}$ & $k_{20}(\mathrm{~cm} / \mathrm{s})$ \\
\hline \multirow{6}{*}{ Fine steel slag } & 1 & 22 & 0.493 & $7.839 \times 10^{-3}$ & 28.2 & 0.833 & $6.53 \times 10^{-3}$ \\
\hline & 2 & 30 & 0.532 & $8.182 \times 10^{-3}$ & 30.8 & 0.781 & $6.39 \times 10^{-3}$ \\
\hline & 3 & 45 & 0.615 & $6.376 \times 10^{-3}$ & 29.8 & 0.798 & $5.08 \times 10^{-3}$ \\
\hline & 4 & 47 & 0.625 & $4.610 \times 10^{-3}$ & 28.2 & 0.833 & $3.84 \times 10^{-3}$ \\
\hline & 5 & 66 & 0.690 & $4.034 \times 10^{-3}$ & 28.0 & 0.833 & $3.36 \times 10^{-3}$ \\
\hline & 6 & 75 & 0.724 & $3.821 \times 10^{-3}$ & 29.5 & 0.806 & $3.08 \times 10^{-3}$ \\
\hline \multirow{6}{*}{ Coarse steel slag } & 1 & 9 & 0.567 & $8.9 \times 10^{-2}$ & 32.0 & 0.765 & $6.81 \times 10^{-2}$ \\
\hline & 2 & 33 & 0.605 & $7.4 \times 10^{-2}$ & 28.1 & 0.833 & $6.16 \times 10^{-2}$ \\
\hline & 3 & 47 & 0.635 & $7.073 \times 10^{-2}$ & 28.2 & 0.833 & $5.89 \times 10^{-2}$ \\
\hline & 4 & 53 & 0.661 & $4.66 \times 10^{-2}$ & 17.0 & 1.077 & $5.02 \times 10^{-2}$ \\
\hline & 5 & 60 & 0.720 & $3.2 \times 10^{-2}$ & 18.0 & 1.050 & $3.36 \times 10^{-2}$ \\
\hline & 6 & 69 & 0.824 & $3.05 \times 10^{-2}$ & 18.2 & 1.050 & $3.20 \times 10^{-2}$ \\
\hline \multirow{6}{*}{ Gravel steel slag } & 1 & 38 & 0.422 & $2.77 \times 10^{-2}$ & 18.0 & 1.050 & $2.91 \times 10^{-2}$ \\
\hline & 2 & 50 & 0.482 & $2.38 \times 10^{-2}$ & 18.8 & 1.025 & $2.44 \times 10^{-2}$ \\
\hline & 3 & 56 & 0.510 & $1.61 \times 10^{-2}$ & 17.0 & 1.077 & $1.72 \times 10^{-2}$ \\
\hline & 4 & 68 & 0.592 & $6.4 \times 10^{-3}$ & 18.0 & 1.050 & $6.72 \times 10^{-3}$ \\
\hline & 5 & 72 & 0.620 & $0.99 \times 10^{-4}$ & 18.8 & 1.025 & $1.01 \times 10^{-4}$ \\
\hline & 6 & 78 & 0.715 & $6.80 \times 10^{-5}$ & 18.0 & 1.050 & $7.20 \times 10^{-5}$ \\
\hline
\end{tabular}

The downward trend of curves slowed down when the relative density was more than $60 \%$. The permeability coefficient of gravel steel slag decreased significantly with increasing relative density. The downward trend slowed down when the relative density was more than $70 \%$, and the law was different from that of fine steel slag and coarse steel slag, the reason may be that the gradation of gravel steel slag was better, which can be seen from Table 2 .

\subsubsection{Relationship between Permeability Coefficient and} Porosity Ratio. According to specific gravities of the three kinds of steel slag, as shown in Table 4, porosity ratios under each state were calculated by using formula (4) below, as shown in Table 7 . The curves of the permeability coefficient versus the porosity ratio of steel slag are plotted in Figure 6. It can be seen from the figure that the permeability coefficient of steel slag increased with increasing the porosity ratio, which increased rapidly with the porosity ratio in the range of 0.5 to 0.65 , and then the growth trend tended to be gentle:

$$
e=\frac{G_{\mathrm{s}} \rho_{\mathrm{w}}}{\rho_{\mathrm{d}}}-1,
$$

where $G_{\mathrm{s}}$ is the specific gravity of steel slag, $\rho_{\mathrm{d}}$ is the dry density of steel slag, and $\rho_{\mathrm{w}}$ is the water density at $4^{\circ} \mathrm{C}$.

It was found that it was difficult to compact fine steel slag in the process of sample preparation. Water coming out of the adjustment pipe was in the state of water droplet no matter how the void ratio changed. The permeability coefficient was stable at $10^{-3}$ order of magnitude, and the difference of numerical values was not great. Coarse steel slag with poor gradation had more coarse particles and a 


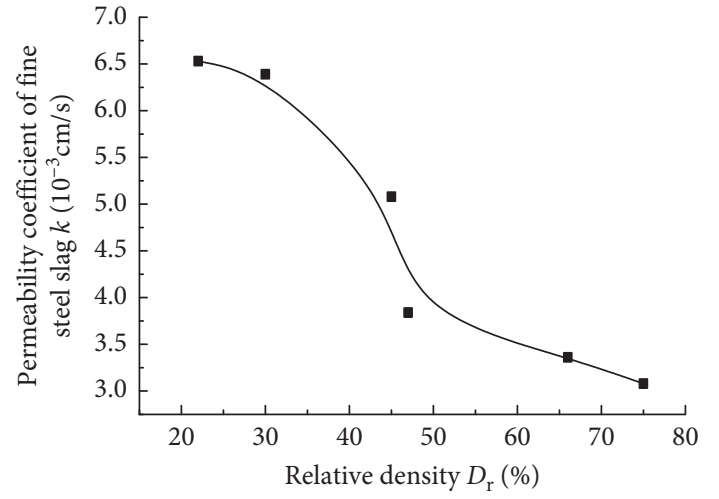

(a)

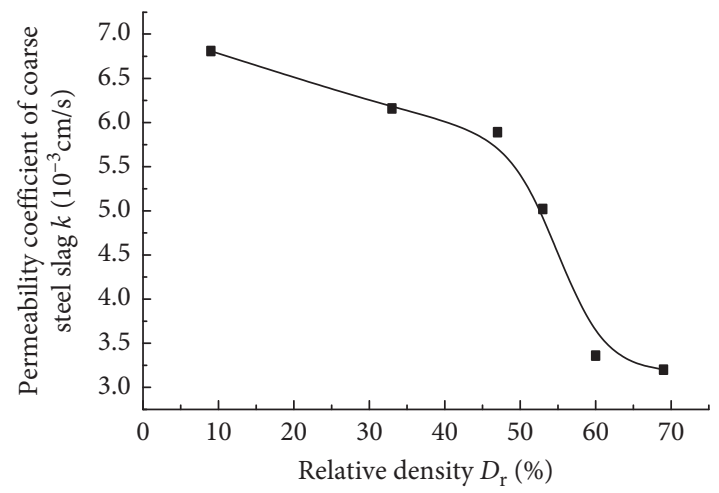

(b)

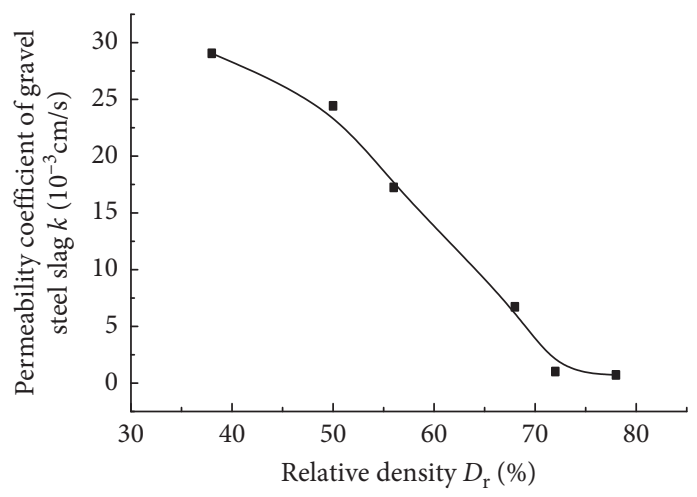

(c)

Figure 5: Curves on the permeability coefficients of three types of steel slag with changing relative density: (a) fine steel slag; (b) coarse steel slag; (c) gravel steel slag.

large range of particle size, so the seepage velocity was significantly faster than fine steel slag with water flow coming out of pipe, and its permeability coefficients were all at $10^{-2}$ order of magnitude. According to the gradation curve, it can be seen that the particle-size distribution range of gravel steel slag was larger. It was easy to compact due to many large particles and good gradation. Water coming out of the pipe changed from water flow to water droplet with decreasing pore ratio. When the porosity ratio was greater than 0.52 and gradually increased, the permeability coefficient of gravel steel slag was at $10^{-2}$ order of magnitude and increased rapidly, whose permeability performance was similar to coarse steel slag. When the porosity ratio was less than 0.52 and gradually decreased, the permeability coefficient of gravel steel slag was very small with its order of magnitude passing from $10^{-3}$ and reaching $10^{-4}$ or even smaller.

\subsubsection{Prediction Formula on Permeability Coefficient of Pure} Steel Slag. Due to the limitation of functions of the infiltration instrument, steel slag could not be completely compacted during the test. In order to fully understand permeability characteristics of steel slag under different conditions, it was necessary to deduce the prediction formula on the permeability coefficient of pure steel slag, which could be modified based on empirical formulas on the permeability coefficient of traditional soils proposed by predecessors, or its fitting formula could be deduced based on test data of this paper.

Research findings of predecessors about prediction formulas on the permeability coefficient of traditional soils are mainly as follows [21]: Hazen [22] proposed the empirical formula of the permeability coefficient, as shown in formula (5) below, basing on the test data obtained by permeability tests of pure sand, where $c$ is a constant varying from 1 to 1.5. The formula cannot be applied when sand contains a small amount of silt or clay. Casagrande proposed the simple relationship on the permeability coefficient of fine sand and medium sand, as shown in formula (6) below, showing that the permeability coefficient was related to the porosity ratio and the permeability coefficient corresponding to porosity ratios less than 0.85 . Kozeny [23] deduced the formula on the permeability coefficient of new coarse grained soil, as shown in formula (7) below. Amer and Awad [24] obtained formula (8) on the permeability coefficient based on previous studies and results of his own tests, where $C_{1}$ is a constant:

$$
\begin{aligned}
& k=c d_{10}^{2}, \\
& k=1.4 e^{2} k_{0.85},
\end{aligned}
$$




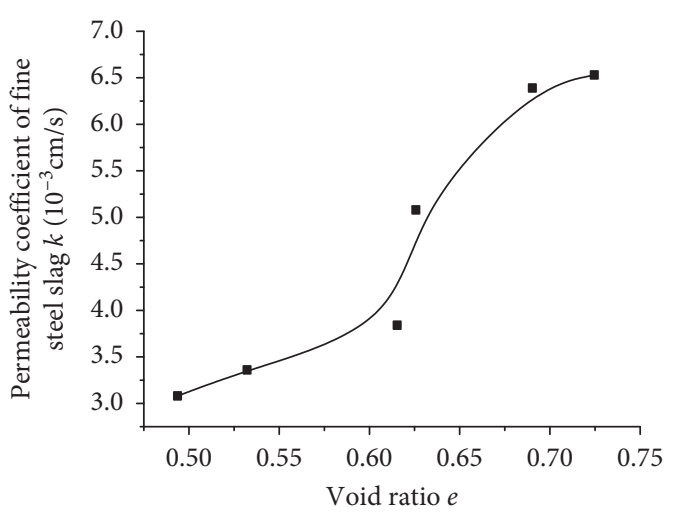

(a)

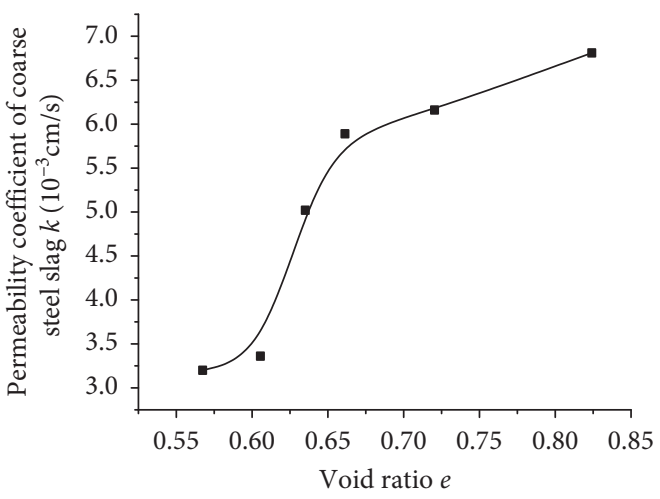

(b)

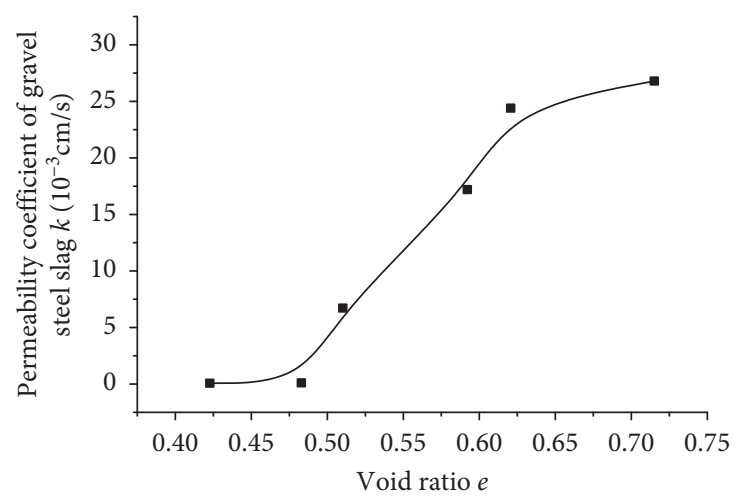

(c)

FIGURE 6: Permeability curves of three kinds of steel slag with changing void ratios: (a) fine steel slag; (b) coarse steel slag; (c) gravel steel slag.

$$
\begin{aligned}
& k=\frac{1}{C_{\mathrm{s}} S_{\mathrm{s}} T^{2}} \frac{\gamma_{\mathrm{w}}}{\mu} \frac{e^{3}}{1+e^{3}}, \\
& k=C_{1} d_{10}^{2.32} C_{\mathrm{u}}^{0.6} \frac{e^{3}}{1+e^{3}} .
\end{aligned}
$$

The previous formula showed that the permeability coefficient of coarse grained soil has a relationship with the porosity ratio, that is,

$$
k \propto \frac{e^{3}}{1+e^{3}}
$$

Chapuis [25] proposed an empirical relational equation on $k$, as shown in equation (10) below, which is valid for natural, uniform sand and gravel. The predicted range of the permeability coefficient is $10^{-1}$ to $10^{-3}$ and can be extended and used in the natural silt without plasticity, but it is invalid for crushed materials or silt with a certain degree of plasticity:

$$
k=2.4622\left[d_{10}^{2} \frac{e^{3}}{1+e^{3}}\right]^{0.7825}
$$

The waste steel slag studied in this paper is a broken material with gelling and cohesive characteristics, but macroscopic particles are similar to sand and gravel. Therefore, the formula for calculating the permeability coefficient of steel slag could be modified based on the empirical formula of Chapuis. After calculation, it was found that the modified Chapuis formula was applicable for calculating the permeability coefficient of fine steel slag and coarse steel slag, as shown in the following formulas:

$$
\begin{aligned}
& k=41.86\left[d_{10}^{2} \frac{e^{3}}{1+e^{3}}\right]^{0.7825}, \\
& k=195.38\left[d_{10}^{2} \frac{e^{3}}{1+e^{3}}\right]^{0.7825} .
\end{aligned}
$$

The deviation between test values and formula calculation values of the permeability coefficient is listed in Table 8.

The deviation between the two kinds of values of fine steel slag was very small, except for the individual deviation of about $20 \%$, and other deviations were all within $10 \%$. The deviation between the two kinds of values of coarse steel slag was relatively small, but there were two deviations more than $20 \%$. However, whether fine steel slag or coarse steel slag, prediction values and test values of permeability coefficient were at the same order of magnitude, indicating that the two correction formulas proposed in this paper were reasonable and reliable in predicting the permeability coefficient of coarse and fine steel slag.

The changing range of the permeability coefficient of gravel steel slag under different densities was wide, stretching across 4 orders of magnitude, from $10^{-5}$ to $10^{-2}$. 
TABLE 8: Comparison between test values and formula calculation values on the permeability coefficient of fine steel slag and coarse steel slag.

\begin{tabular}{|c|c|c|c|c|c|}
\hline Type of steel slag & $d_{10}(\mathrm{~mm})$ & $E$ & Test value $\left(10^{-3} \mathrm{~cm} / \mathrm{s}\right)$ & Calculation value $\left(10^{-3} \mathrm{~cm} / \mathrm{s}\right)$ & Deviation (\%) \\
\hline \multirow{6}{*}{ Fine steel slag } & 0.13 & 0.4937 & 3.08 & 2.998 & 2.65 \\
\hline & 0.13 & 0.5322 & 3.36 & 3.502 & -4.23 \\
\hline & 0.13 & 0.6154 & 3.84 & 4.666 & -21.51 \\
\hline & 0.13 & 0.6257 & 5.08 & 4.815 & 5.21 \\
\hline & 0.13 & 0.6903 & 6.39 & 5.762 & 9.82 \\
\hline & 0.13 & 0.7246 & 6.53 & 6.267 & 4.02 \\
\hline \multirow{6}{*}{ Coarse steel slag } & 0.21 & 0.5674 & 3.2 & 3.971 & -24.10 \\
\hline & 0.21 & 0.6055 & 3.36 & 4.509 & -34.19 \\
\hline & 0.21 & 0.6351 & 5.02 & 4.935 & 1.68 \\
\hline & 0.21 & 0.6613 & 5.89 & 5.318 & 9.71 \\
\hline & 0.21 & 0.7204 & 6.16 & 6.186 & -0.42 \\
\hline & 0.21 & 0.8241 & 6.81 & 7.681 & -12.79 \\
\hline \multirow{6}{*}{ Gravel steel slag } & 0.27 & 0.4227 & 0.72 & 0.972 & -35.03 \\
\hline & 0.27 & 0.4829 & 1.01 & 1.119 & -10.80 \\
\hline & 0.27 & 0.5102 & 67.2 & 46.187 & 31.27 \\
\hline & 0.27 & 0.5921 & 172 & 186.557 & -8.46 \\
\hline & 0.27 & 0.6207 & 244 & 231.389 & 5.17 \\
\hline & 0.27 & 0.7151 & 291 & 293.437 & -0.84 \\
\hline
\end{tabular}

By checking, it was found that the previous empirical formulas are not applicable for calculating the permeability coefficient and they cannot be corrected. Therefore, the fitting formula applicable for calculating the permeability coefficient of gravel steel slag was deduced as shown in formula (13) below by using the obtained test data for fitting the curve. Curves of the permeability coefficient versus the porosity ratio of gravel steel slag are plotted in Figure 7. The fitting degree of the calculation formula on the permeability coefficient of gravel steel slag was $97.2 \%$.

$$
k=1.02 \times 10^{5} \frac{e^{14.62}}{1+3341.44 e^{14.62}},
$$

\section{Test on Permeability Characteristics of Steel Slag-Treated Silt Soil}

The order of magnitude of the permeability coefficient of pure silt was less than $10^{-7}$, and the infiltration capacity was very weak. The order of magnitude of the permeability coefficient of pure steel slag was in the range of $10^{-4}$ to $10^{-2}$ known from previous studies. Therefore, this paper intended to increase the permeability performance of silt soil by adding steel slag.

4.1. Test Materials. The silt selected for tests was silt soil for sea reclamation of the seaside Avenue in Lianyungang Ctiy, Jiangsu Province, China, with a natural water content of $53.3 \%$, a wet density of $1.73 \mathrm{~g} / \mathrm{cm}^{3}$, and a specific gravity $G_{s}$ of 2.74. The permeability coefficient of the initial test was at the order of magnitude $10^{-7}$, and the infiltration capacity was weak. In previous tests, it was found that gravel steel slag has strong water-absorbing ability. Therefore, gravel steel slag whose grain size groups were particle sizes less than $2 \mathrm{~mm}$ was added into silt to test the permeability coefficient of silt soil modified by using steel slag. The mass ratio of silt and steel slag was formulated according to $1: 0,1: 0.3,1: 0.5$,

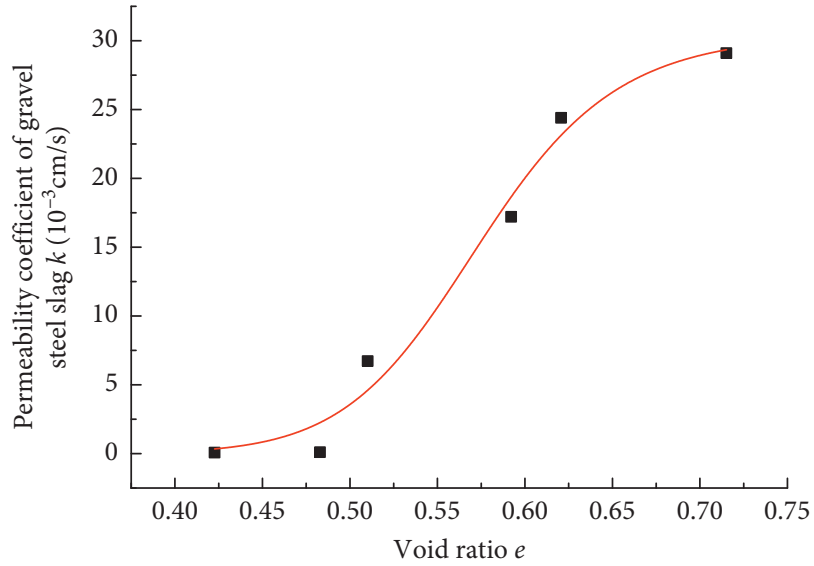

Figure 7: Fitting curve on the permeability coefficient of gravel steel slag.

$1: 0.7,1: 0.9$, and $1: 1.1$ described as $0 \%, 30 \%, 50 \%, 70 \%$, $90 \%$, and $110 \%$ in the paper below basing on the quality of dry silt, which was known as the mixing ratio of steel slag and recorded as $\alpha$.

4.2. Test Equipment and Test Methods. Because silt soil is a fine grained soil, the selected test equipment is a TST-55type permeameter with a variable water head produced by Nanjing Soil Instrument Co., Ltd, as shown in Figure 8. The diameter of soil wreath knife is $6.18 \mathrm{~cm}$, whose height is $4 \mathrm{~cm}$ and bottom area is $A$. Test water was degassed by the boiling method, and the water temperature was $3^{\circ} \mathrm{C}$ to $4^{\circ} \mathrm{C}$ higher than indoor temperature.

After drying and grinding silt, steel slag was added with different proportions. The undisturbed silt soil was placed in the soil wreath knife with smoothing surface of the sample when the permeability test of pure silt was carried out, as shown in Figure 9. Dried silt soil and steel slag were mixed 


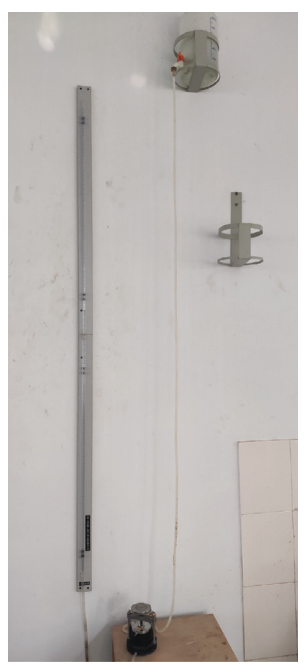

(a)

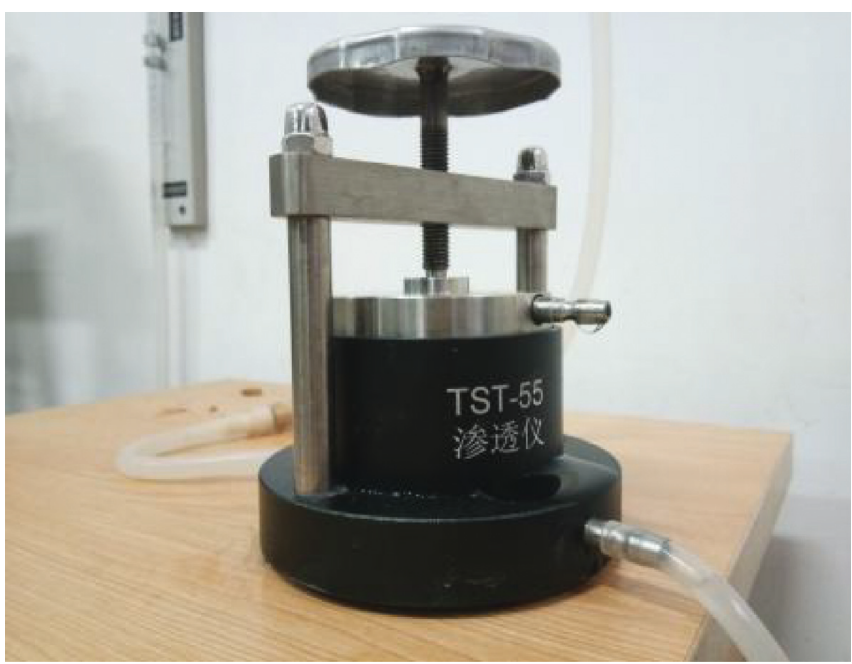

(b)

FIgURE 8: Variable head permeability test device. (a) Variable water head tube fixed on the wall. (b) Permeability meter.

and homogenized during sample preparation, and the compaction method was adopted to compact the sample in layers with hitting 10 times in each layer for controlling the compactness. After the sample was made, it was put in the air exhaust and water saturation cylinder, as shown in Figure 10, exhausting air for 10 minutes and saturating for over 10 hours.

After the sample was completely saturated, according to the standard of the soil test method, the soil wreath knife with the sample in it was placed in the permeameter, and then the nut was screwed tightly for sealing the device without water leakage and air leakage. The inlet pipe switch was opened to make the water to flow out of the air exhaust holez and the exhaust valve and inlet pipe were closed when no air bubbles existed in the exhaust valve. Water was injected into the variable head pipe to a predetermined height. When water overflowed from the water outlet, the water level of the variable head pipe and the starting time were recorded. The change of water head and time were recorded at predetermined time intervals, and water temperatures of water outlet were measured. Three parallel experiments were conducted by changing the height of water level using the variable head pipe, and then their average value was taken.

4.3. Test Results and Analysis. The permeability coefficient of the variable head was calculated according to the following formula:

$$
k_{\mathrm{T}}=2.3 \frac{a L}{A\left(t_{2}-t_{1}\right)} \log \frac{H_{2}}{H_{1}},
$$

where $a$ is the sectional area of the variable head tube $\left(\mathrm{cm}^{2}\right)$, 2.3 is the change factor of $\ln$ and $\log , L$ is the seepage path length, that is, the height of the sample $(\mathrm{cm}), t_{2}$ and $t_{1}$ are, respectively, the beginning and ending time of reading water head (s), and $H_{1}$ and $H_{2}$ are, respectively, the beginning and stopping water head $(\mathrm{mm})$.

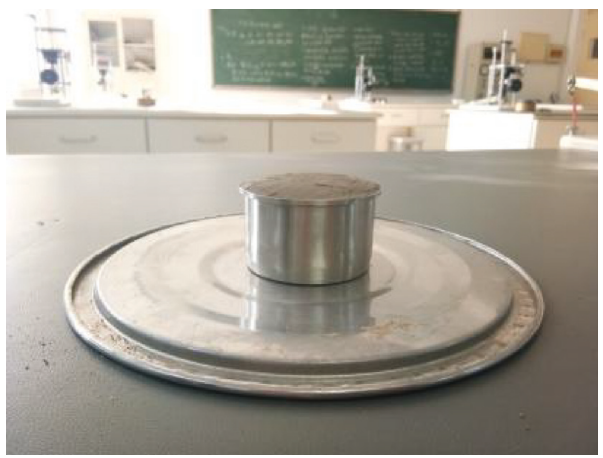

FIgURE 9: Sample in the soil wreath knife.

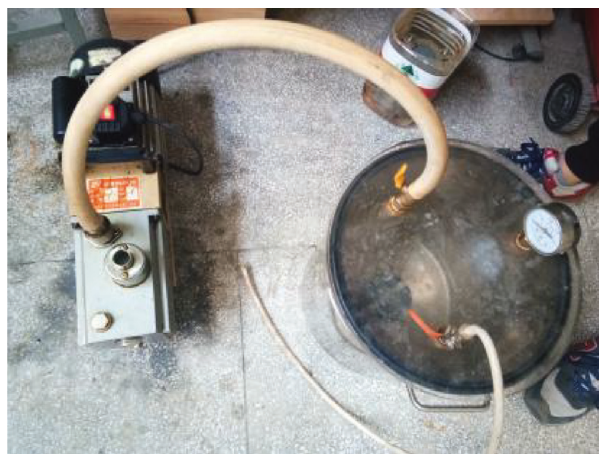

FiguRE 10: Air exhaust and water saturation of the sample.

The test value is the permeability coefficient $k_{\mathrm{T}}$ of steel slag-treated silt soil at room temperature, which was transformed into the permeability coefficient $k_{20}$ according to the previous formula (3). The test results are shown in Table 9.

The curve of the permeability coefficient versus mixing content of steel slag was plotted in Figure 11(a) according to the data in Table 10, where the permeability coefficient of the ordinate in Figure 11(b) was expressed in logarithmic form 
Table 9: Permeability coefficient of modified silt with different amounts of steel slag.

\begin{tabular}{|c|c|c|c|c|}
\hline Mixing ratio of steel slag & Average water temperature $T\left({ }^{\circ} \mathrm{C}\right)$ & $k_{\mathrm{T}}(\mathrm{cm} / \mathrm{s})$ & $\eta_{\mathrm{T}} / \eta_{20}$ & $k_{20}(\mathrm{~cm} / \mathrm{s})$ \\
\hline \multirow{3}{*}{$0 \%$} & 15.0 & $1.691 \times 10^{-7}$ & 1.133 & \multirow{3}{*}{$1.920 \times 10^{-7}$} \\
\hline & 14.5 & $1.676 \times 10^{-7}$ & 1.148 & \\
\hline & 14.5 & $1.692 \times 10^{-7}$ & 1.148 & \\
\hline \multirow{3}{*}{$30 \%$} & 13.7 & $3.348 \times 10^{-6}$ & 1.178 & \multirow{3}{*}{$3.923 \times 10^{-6}$} \\
\hline & 13.7 & $3.312 \times 10^{-6}$ & 1.178 & \\
\hline & 13.5 & $3.39 \times 10^{-6}$ & 1.178 & \\
\hline \multirow{3}{*}{$50 \%$} & 14.2 & $5.307 \times 10^{-6}$ & 1.163 & \multirow{3}{*}{$6.131 \times 10^{-6}$} \\
\hline & 14.1 & $5.236 \times 10^{-6}$ & 1.163 & \\
\hline & 14.0 & $5.281 \times 10^{-6}$ & 1.163 & \\
\hline \multirow{3}{*}{$70 \%$} & 13.5 & $3.155 \times 10^{-5}$ & 1.178 & \multirow{3}{*}{$3.467 \times 10^{-5}$} \\
\hline & 13.5 & $2.827 \times 10^{-5}$ & 1.178 & \\
\hline & 13.5 & $2.847 \times 10^{-5}$ & 1.178 & \\
\hline \multirow{3}{*}{$90 \%$} & 13.0 & $8.99 \times 10^{-5}$ & 1.194 & \multirow{3}{*}{$1.011 \times 10^{-4}$} \\
\hline & 13.0 & $9.15 \times 10^{-5}$ & 1.194 & \\
\hline & 13.0 & $7.27 \times 10^{-5}$ & 1.194 & \\
\hline \multirow{3}{*}{$110 \%$} & 11.9 & $1.97 \times 10^{-4}$ & 1.227 & \multirow{3}{*}{$3.276 \times 10^{-4}$} \\
\hline & 11.8 & $3.19 \times 10^{-4}$ & 1.227 & \\
\hline & 11.8 & $2.85 \times 10^{-4}$ & 1.227 & \\
\hline
\end{tabular}

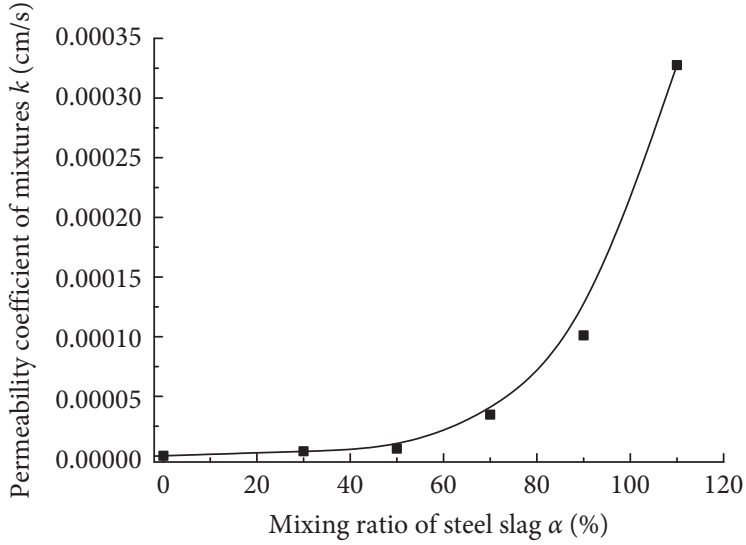

(a)

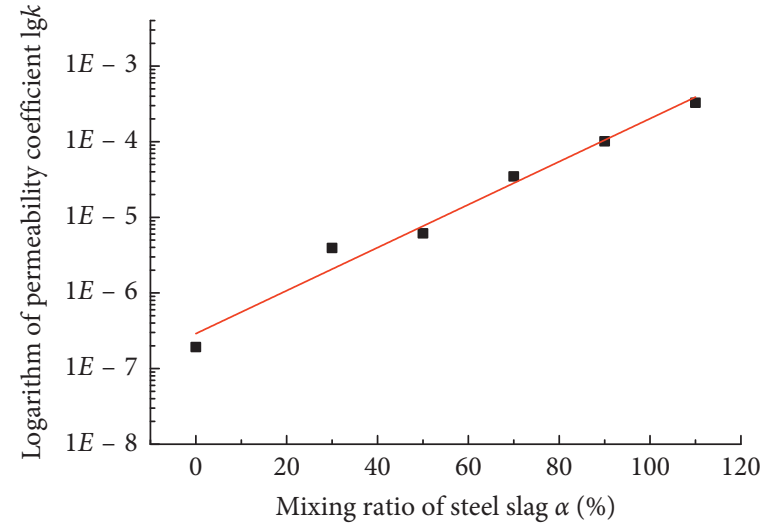

(b)

FIGURE 11: Fitting curves on the permeability coefficient of steel slag-treated silt soil.

TABle 10: Permeability coefficients of steel slag and traditional soils.

\begin{tabular}{lccc}
\hline Material type & Permeability coefficient $(\mathrm{cm} / \mathrm{s})$ & Material type & Permeability coefficient $(\mathrm{cm} / \mathrm{s})$ \\
\hline Fine steel slag & $1 \times 10^{-3} \sim 8.9 \times 10^{-3}$ & Pure gravel & $>10^{-1}$ \\
Coarse steel slag & $1 \times 10^{-2} \sim 9.2 \times 10^{-2}$ & Mixture of pure sand and gravel & $10^{-3} \sim 10^{-1}$ \\
Gravel steel slag & $3 \times 10^{-5} \sim 5 \times 10^{-2}$ & Mixture of silt, sand, and clay & $10^{-7} \sim 10^{-5}$ \\
Fly ash [9] & $10^{-5} \sim 10^{-3}$ & Fine sand & $10^{-5} \sim 10^{-3}$ \\
Clay [26] & $<10^{-7}$ & Steel slag-treated silt soil & $10^{-7} \sim 10^{-3}$ \\
\hline
\end{tabular}

and the coordinate system was a single logarithm coordinate system. As can be seen from the distribution of data points in Figure 11(a), the permeability coefficient of modified silt soil increased continuously with increasing mixing content of steel slag. The growth rate of the permeability coefficient increased obviously when mixing content of steel slag was more than $50 \%$, and the growth trend being like exponential function relationship. From the test data, the permeability coefficient of pure silt was $1.92 \times 10^{-7}$. The permeability coefficient increased suddenly by an order of magnitude, reaching $10^{-6}$ when adding steel slag of $30 \%$ to silt. The permeability coefficient increased by two orders of magnitude, reaching $10^{-5}$ when adding steel slag of $70 \%$ to silt. The permeability coefficient increased by three orders of magnitude, reaching $10^{-4}$ when adding steel slag of $90 \%$ to silt. It can be seen that the permeability performance of silt soil can be greatly improved by adding steel slag.

According to the change rule of data of permeability coefficients in Figure 11(b), it can be seen that the linear function in the single logarithmic coordinate system can 


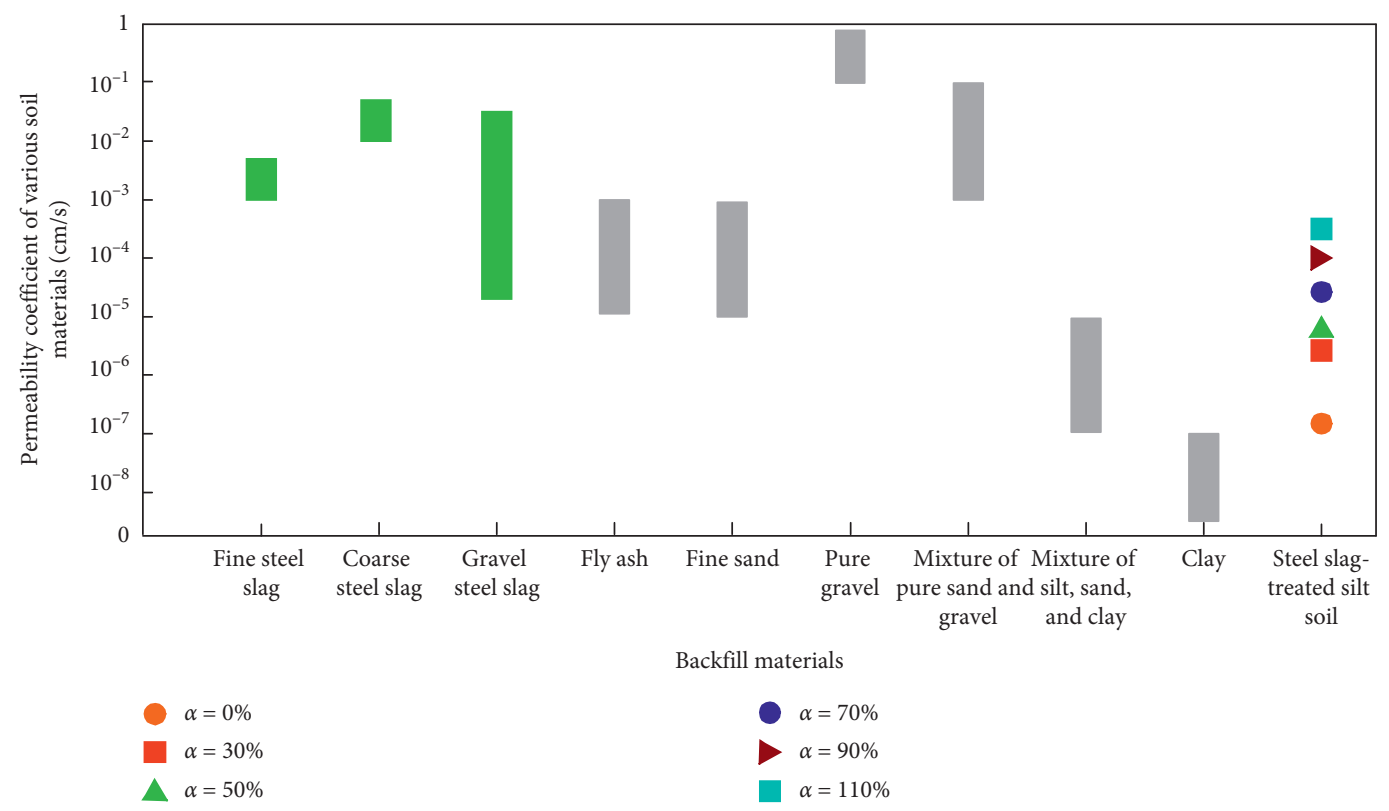

Figure 12: Comparison of permeability coefficients between steel slag, steel slag-treated silt soil, and traditional soils.

better simulate the changing rule of the permeability coefficient of steel slag-treated silt soil with different mixing ratios of steel slag. Therefore, the linear fitting formula of the permeability coefficient in the single logarithmic coordinate system is shown in formula (15) below. The relationship between the permeability coefficient of steel slag-treated silt soil and the mixing ratio of steel slag was obtained by transforming formula (15), as shown in formula (16) below. It can be seen that the relationship between the permeability coefficient of steel slag-treated silt soil and the mixing ratio of steel slag is the exponential function:

$$
\begin{aligned}
\lg k & =0.0276 \alpha-6.5229, \\
k & =10^{0.0276 \alpha-6.5229} .
\end{aligned}
$$

\section{Comparison with Traditional Geotechnical Backfill Materials}

In order to widely use the steel slag in geotechnical engineering, it is necessary to compare permeability characteristics of steel slag with those of traditional soils. Permeability coefficients of different types of steel slag and traditional soils are listed in Table 10.

In order to clearly compare ranges of the permeability coefficient of steel slag and traditional soils, the histogram was drawn as shown in Figure 12. The permeability coefficients of the three kinds of pure steel slag, steel slagtreated silt soil, and traditional soils were compared. It was concluded that the permeability performance of gravel steel slag in dense states with relative densities more than 55\% was equivalent to that of fly ash [27]; the order of magnitude being in the range of $10^{-5}$ to $10^{-3}$. The permeability performance of coarse steel slag and fine steel slag was better than that of fly ash whose range of order of magnitude of the permeability coefficient was $10^{-5}$ to $10^{-3}$, inferior to pure gravel whose order of magnitude was more than $10^{-1}$, and equivalent to the mixture of pure sand and low content of gravel. The order of magnitude of the permeability coefficient increased from $10^{-7}$ to $10^{-3}$ with increasing mixing content of steel slag in the process of modifying silt soil. Therefore, on the whole, the permeability performance of steel slag is good and the effect of steel slag-treated silt soil is good.

\section{Geotechnical Applications of Steel Slag}

Traditional sand and fly ash were often used as roadbed backfill material. But as sand and fly ash basically do not have cementitious performance and cohesion, sand will be easily destroyed by water flow and wind erosion. Fly ash is light, whose water stability is weaker than steel slag. Results showed that permeability characteristics of pure steel slag are good based on previous studies on the three kinds of pure steel slag and steel slag has cementitious performance and cohesion. Therefore, steel slag is more suitable than sand and fly ash as a backfill material for roadbed, foundations, and other engineering.

A roadbed backfill material must have good water permeability. It was concluded from previous studies that the permeability performance of gravel steel slag with relative densities more than $55 \%$ was equivalent to that of fly ash and the permeability performance of fine steel slag and coarse steel slag were better than that of fly ash and equivalent to the mixture of pure sand and low content of gravel. Therefore, fine steel slag, coarse steel slag, and gravel steel slag in dense states can replace fly ash in geotechnical applications, and fine steel slag and coarse steel slag can also replace the mixture of pure sand and low content of gravel.

Except that steel slag is directly backfilled to subgrade and foundation projects mentioned in the preceding 
paragraph, steel slag can also be used to reinforce and modify soft clay. It was concluded from previous studies that the permeability performance of silt soil is poor. Using gravel steel slag-treated silt soil can not only reduce the water content in silt soil but also improve its infiltration capacity. The permeability coefficient can reach the order of magnitude more than $10^{-5}$ when more than $70 \%$ of steel slag was added to silt soil. The permeability of silt can be improved by adding steel slag in backfill and treatment projects, thus improving the water permeability of soft soil foundations.

\section{Conclusions}

The permeability of steel slag and steel slag-treated silt soil were researched for the first time and some conclusions could be drawn as follows:

(1) The permeability coefficient of fine steel slag was at $10^{-3}$ order of magnitude. The seepage velocity of coarse steel slag was significantly faster than that of fine steel slag, and the permeability coefficient was at $10^{-2}$ order of magnitude. The permeability coefficient of gravel steel slag was in the range of $10^{-5}$ to $10^{-2}$. The Chapuis formula could be applied to calculate the permeability coefficient of fine steel slag and coarse steel slag.

(2) The permeability performance of gravel steel slag in dense states with relative densities more than 55\% was equivalent to that of fly ash. The permeability performance of coarse steel slag and fine steel slag was better than that of fly ash, inferior to pure gravel and equivalent to pure sand and the mixture of sand and gravel with low content.

(3) The permeability performance of silt soil could greatly be improved by adding steel slag. The growth rate of the permeability coefficient of steel slagtreated silt soil increased obviously. When the mixing content of steel slag was more than $50 \%$, the growth trend of the permeability coefficient was like exponential function relationship.

(4) The linear function in a single logarithmic coordinate system could simulate the changing rule of the permeability coefficient of steel slag-treated silt soil with different mixing contents of steel slag. The exponential function could describe the relationship between the permeability coefficient of steel slagtreated silt soil and the mixing ratio of steel slag.

(5) Fine steel slag, coarse steel slag, and gravel steel slag at the dense state can replace fly ash in geotechnical applications, and fine steel slag and coarse steel slag can also replace pure sand and the mixture of pure sand and gravel with low content. The permeability of silt can be improved by adding steel slag in soft foundation treatment.

\section{Data Availability}

Data are available upon request to the corresponding author.

\section{Conflicts of Interest}

The authors declare that there are no conflicts of interest regarding the publication of this paper.

\section{Acknowledgments}

This study was supported by the Jiangsu Natural Science Foundation of China (BK20161360), Jiangsu Province "Six Top Talent Peak Funding Plan" (2016-JZ-020), and Postgraduate Research and Practice Innovation Program of Jiangsu Province (SJCX18_0773).

\section{References}

[1] P. Zhang, Z. Zhao, and H. Wu, "Coarse particle effects of permeability coefficient of sand," Water Saving Irrigation, vol. 25, no. 11, pp. 25-27, 2013.

[2] D. Perraton and A. Carter, "In-situ permeability of the outermost layer of asphalt and cement concrete road materials water permeability evaluated with gas flow," Road Materials and Pavement Design, vol. 6, no. 2, pp. 239-253, 2005.

[3] F. C. Wang, X. N. Feng, H. Gong, and H. Y. Zhao, "Study of permeability of glass-sand soil," Archives of Civil Engineering, vol. 63, no. 3, pp. 175-190, 2017.

[4] M. Ş. Özçoban, S. G. Durak, T. O. Acar, G. T. Demirkol, S. Ö. Çelik, and N. Tüfekci, "Evaluation of clay soils' permeability: a comparative study between the natural, compacted, and consolidated clay soils," Journal of Advances in Technology and Engineering Studies, vol. 3, no. 5, pp. 184-191, 2017.

[5] Y. Zhao, H. Zhang, Q. Lu, and L. Xiaobo, "Experimental study of unsaturated permeability coefficient of compacted loess," Rock and Soil Mechanics, vol. 31, no. 6, pp. 1809-1812, 2010.

[6] D. Yu, H. Yang, and Y. Lize, "Experimental study on permeability coefficient of silty sand subgrade," Communications Science and Technology Heilongjiang, vol. 40, no. 12, p. 30, 2012.

[7] H. Guo, Y. Luo, and Y. Yang, "Permeability characteristic of fly ash added by loess," Journal of Northwest A \& F University, vol. 37, no. 9, pp. 219-223, 2009.

[8] C. Xu, C. Li, and Z. Kai, "Study on the method of measuring the permeability coefficient of red layer filling," Subgrade Engineering, vol. 37, no. 3, pp. 122-124, 2008.

[9] L. Su, Y. Zhang, and W. Tiexing, "Investigation on permeability of sands with different particle sizes," Rock and Soil Mechanics, vol. 35, no. 5, pp. 1289-1294, 2014.

[10] Y. Huang, R. N. Bird, and O. Heidrich, "A review of the use of recycled solid waste materials in asphalt pavements," Resources, Conservation and Recycling, vol. 52, no. 1, pp. 58-73, 2007.

[11] W.-T. Tsai, "Analysis of the sustainability of reusing industrial wastes as energy source in the industrial sector of Taiwan," Journal of Cleaner Production, vol. 18, no. 14, pp. 1440-1445, 2010.

[12] A. E. A. E-M. Behiry, "Evaluation of steel slag and crushed limestone mixtures as subbase material in flexible pavement," Ain Shams Engineering Journal, vol. 4, pp. 43-53, 2013.

[13] P. Sun and G. Zhancheng, "Research progress on cementitious activity and its activation of steel slag," Bulletin of The Chinese Ceramic Society, vol. 33, no. 9, pp. 2230-2235, 2014.

[14] L.-y. Wang, H.-1. Liu, P.-m. Jiang, and X.-x. Chen, "Prediction method of seismic residual deformation of caisson quay wall 
in liquefied foundation," China Ocean Engineering, vol. 25, no. 1 , pp. $45-58,2011$.

[15] L. Liu, S. K. Chen, and P. Gao, "Research on seismic internal forces of geogrids in reinforced soil retaining wall structures under earthquake actions," Journal of Vibroengineering, vol. 16, no. 4, pp. 2023-2034, 2014.

[16] L. Wang, G. Chen, P. Gao, and S. K. Chen, "Pseudo-static calculation method of the seismic residual deformation of a geogrid reinforced soil retaining wall with a liquefied backfill," Journal of Vibroengineering, vol. 17, no. 2, pp. 827-840, 2015.

[17] W.-x. Gong, L.-y. Wang, J. Li, and B.-h. Wang, "Displacement calculation method on front wall of covered sheet-pile wharf," Advances in Civil Engineering, vol. 2018, Article ID 5037057, 13 pages, 2018.

[18] T.-h. Lu, Soil Mechanics, Hohai University Press, Nanjing, China, 2005.

[19] Y. Chen, P. Yu, and L. Shaofen, "Fundamental properties of fly ash," Chinese Journal of Geotechnical Engineering, vol. 10, no. 5, pp. 3-16, 1998.

[20] GB/T 50123-1999 Standard for Soil Test Method, The Ministry of Water Resources of the People's Republic of China, China Planning Press, Beijing, China, 1999.

[21] B. M. Das, Advanced Soil Mechanics, Taylor \& Francis 270 Madison Ave, New York, NY, USA, 2008.

[22] A. Hazen, "Discussion of "dams on sand foundation" by A. C. Koenig," Transactions of the American Society of Civil Engineers, vol. 73, p. 199, 1911.

[23] J. Kozeny, “Theorie und Berechnung der Brunnen," Wasserkr. Wasserwritsch, vol. 28, p. 104, 1933.

[24] A. M. Amer and A. A. Awad, "Permeability of cohesionless soils," American Society of Civil Engineers, vol. 100, no. 12, pp. 1309-1316, 1974.

[25] R. P. Chapuis, "Predicting the saturated hydraulic conductivity of sand and gravel using effective diameter and void ratio," Canadian Geotechnical Journal, vol. 41, no. 5, pp. 785-595, 2004.

[26] H.-n. Feng, Y.-h. Yang, and X.-n. Gong, "Experimental study on engineering characteristics of fly ash," Rock and Soil Mechanics, vol. 23, no. 5, pp. 579-582, 2002.

[27] S. Sui, H. Long, and Z. Ruiping, "Test analysis of the fly ash's geotechnical properties for road use," Journal of Materials Science \& Engineering, vol. 35, no. 7, pp. 289-283, 2017. 


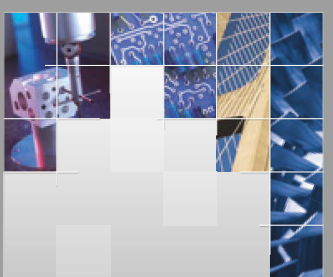

\section{Enfincering}
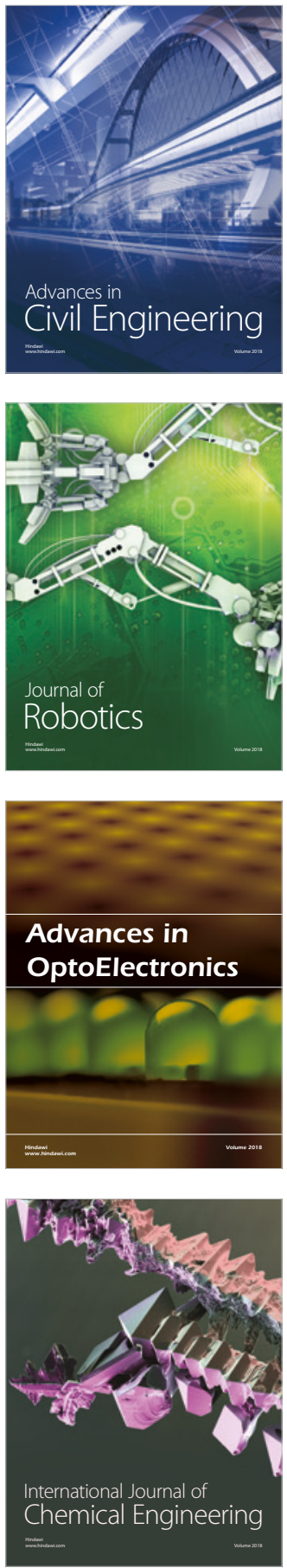

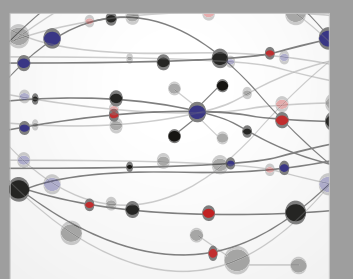

\section{Rotating \\ Machinery}

The Scientific World Journal

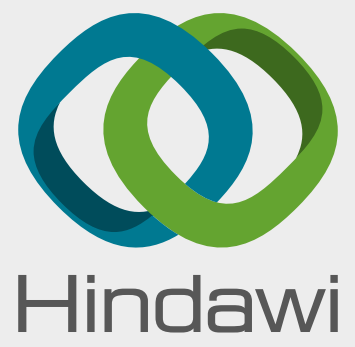

Submit your manuscripts at

www.hindawi.com
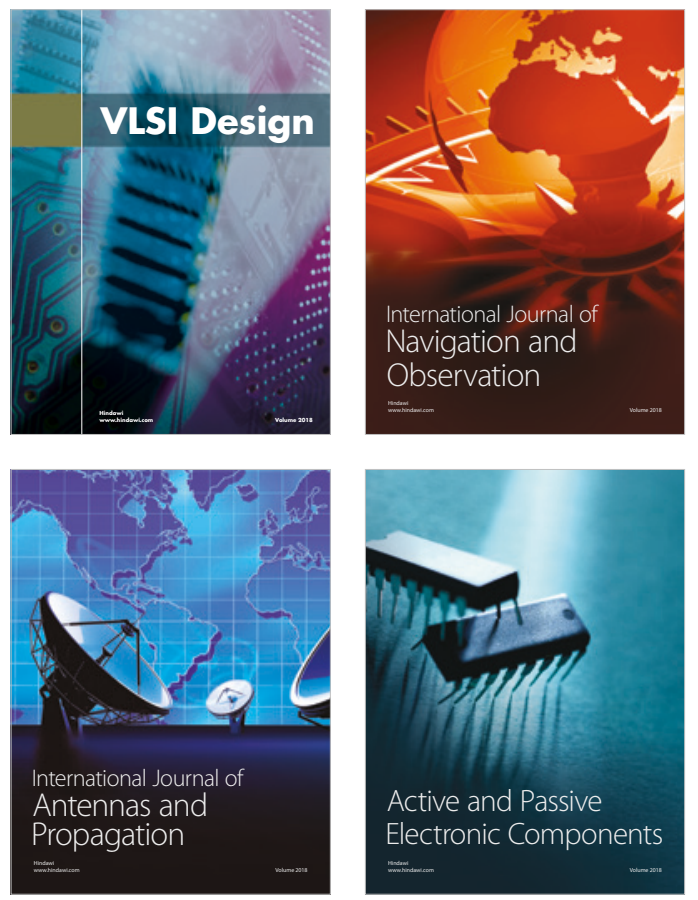
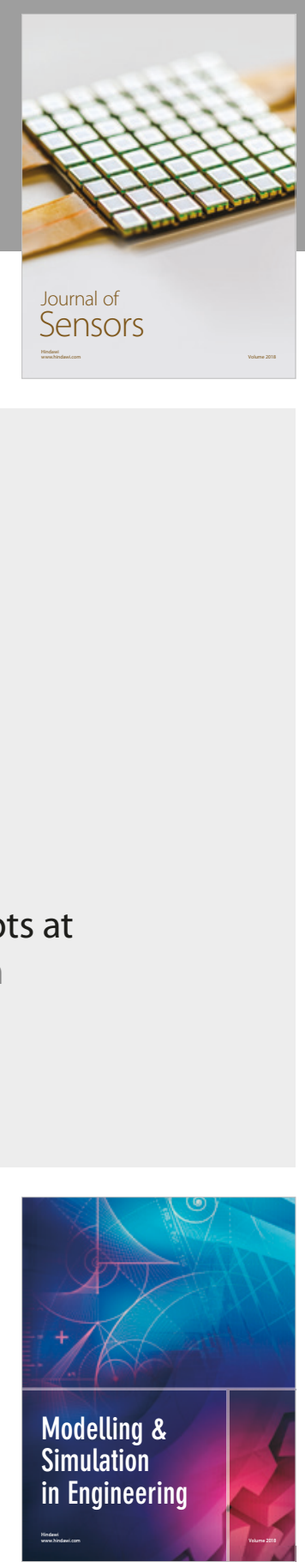

\section{Advances \\ Multimedia}
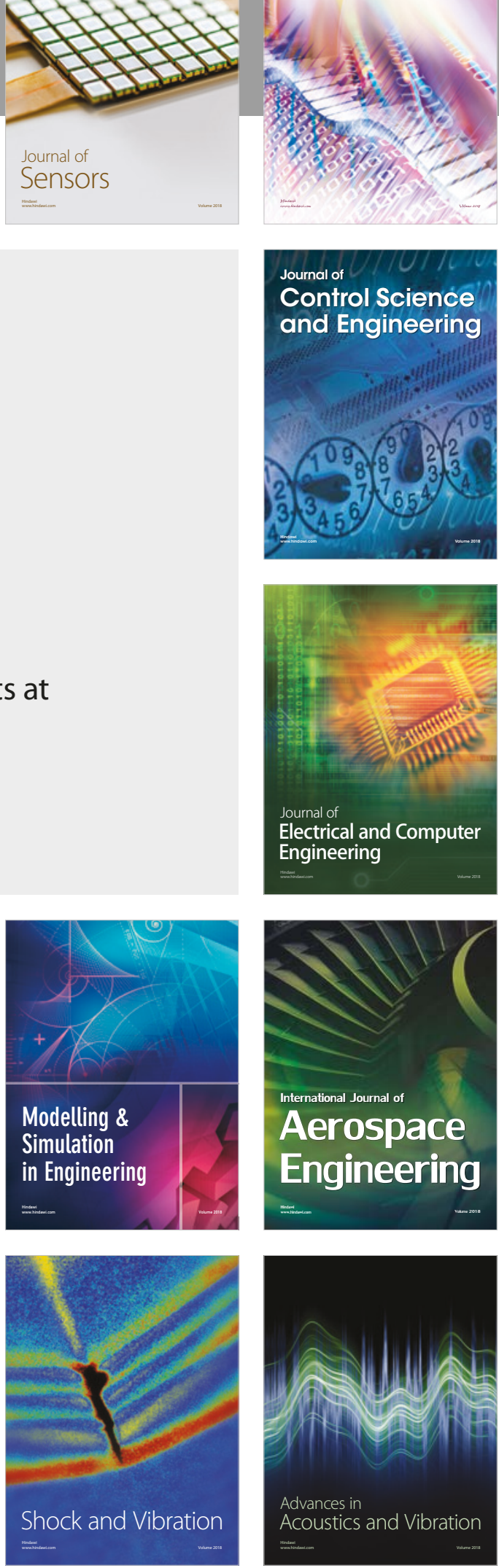